\title{
Cigarette smoking and DNA methylation
}

\section{Ken W. K. Lee and Zdenka Pausova*}

Physiology and Experimental Medicine, The Hospital for Sick Children, University of Toronto, Toronto, ON, Canada

\section{Edited by:}

Trygve Tollefsbol, University of

Alabama at Birmingham, USA

\section{Reviewed by:}

Craig A. Cooney, Central Arkansas Veterans Healthcare System, USA Sanjay Gupta, Case Western Reserve University, USA

\section{${ }^{*}$ Correspondence:}

Zdenka Pausova, Physiology and Experimental Medicine, The Hospital for Sick Children, University of Toronto, 555 University Avenue, Toronto, ON M5G 1X8, Canada e-mail: zdenka.pausova@sickkids.ca
DNA methylation is the most studied epigenetic modification, capable of controlling gene expression in the contexts of normal traits or diseases. It is highly dynamic during early embryogenesis and remains relatively stable throughout life, and such patterns are intricately related to human development. DNA methylation is a quantitative trait determined by a complex interplay of genetic and environmental factors. Genetic variants at a specific locus can influence both regional and distant DNA methylation. The environment can have varying effects on DNA methylation depending on when the exposure occurs, such as during prenatal life or during adulthood. In particular, cigarette smoking in the context of both current smoking and prenatal exposure is a strong modifier of DNA methylation. Epigenome-wide association studies have uncovered candidate genes associated with cigarette smoking that have biologically relevant functions in the etiology of smoking-related diseases. As such, DNA methylation is a potential mechanistic link between current smoking and cancer, as well as prenatal cigarette-smoke exposure and the development of adult chronic diseases.

Keywords: epigenetics, epigenome, DNA methylation, prenatal exposure, cigarette smoking

\section{INTRODUCTION}

Methylation is a chemical modification of DNA that modulates transcription of genetic information from DNA to RNA and, in this manner, can influence the expression of a given phenotype (normal traits or diseases). The rate of methylation at a given DNA site is a quantitative trait regulated by a complex interplay of genetic and environmental factors. Here, we review the current understanding of this interplay, with a special focus on exposure to cigarette smoking - a common environmental factor acting throughout the human lifespan.

\section{DNA METHYLATION DEFINITION OF DNA METHYLATION}

Methylation of DNA is the addition of a methyl group at the $5^{\prime}$ position of cytosines in $\mathrm{CpG}$ dinucleotides (CpGs; Rakyan et al., 2011). Cytosines in $\mathrm{CpA}, \mathrm{CpC}$, and $\mathrm{CpT}$ dinucleotides can also be methylated, but less frequently (Rakyan et al., 2011). In addition, methylated cytosines can oxidize and form 5hydroxymethylcytosines (Ficz et al., 2011); this event is even less common (Dahl et al., 2011).

DNA methylation at a single $\mathrm{CpG}$ site within a single DNA strand is a binary trait - the site is either methylated or not. But experimental samples, such as DNA extracted from lymphocytes, contain a large number of DNA strands. Some of these strands are methylated and others not; therefore, DNA methylation at a single $\mathrm{CpG}$ site in an experimental sample is a quantitative trait, being a proportion of DNA strands that is methylated (Bibikova et al., 2011).

\section{GENOME DISTRIBUTION OF DNA METHYLATION}

The CpG dinucleotides make up only about $1 \%$ of the human genome, which is less than one-fourth of the expected proportion if they were to be randomly distributed; the lower occurrence of CpGs is thought to be due to a high rate of spontaneous mutations of methylated CpGs to TpGs (Han et al., 2008). The CpG dinucleotides cluster within so-called CpG islands (CGIs), which are usually defined as $500-\mathrm{bp}$ to 2 -kb segments of DNA that exhibit at least 50\% CG content and a ratio of observed CpGs to expected CpGs greater than 0.6 (Han et al., 2008; Rakyan et al., 2011). There are approximately 50,200 CGIs in the human genome; they are found most abundantly in gene promoters and repetitive DNA elements. The repetitive DNA elements are short and long interspersed repeats, or tandem repeats, such as mini- and microsatellites, that make up $>50 \%$ of the genome (Lander et al., 2001). CGIs also exist in gene bodies (especially in exons) but these are less common (Medvedeva et al., 2010).

Not all CpGs are methylated. Bisulfite-DNA sequencing of human chromosomes indicates that up to $30 \%$ of $\mathrm{CpGs}$ are unmethylated (i.e., $<20 \%$ of DNA molecules methylated) and over $40 \%$ of CpGs are hypermethylated (i.e., $>80 \%$ of DNA molecules methylated); the remaining $30 \%$ of CpGs are methylated at an intermediary level (i.e., 20-80\% DNA molecules methylated; Eckhardt et al., 2006). Gene-promoter CpGs are mainly unmethylated, while CpGs in gene bodies and repetitive DNA elements are mostly methylated (Suzuki and Bird, 2008; Maunakea et al., 2010). Finally, methylation levels are often correlated across multiple neighboring CpGs and this co-methylation is stronger for CpGs inside CGIs than outside CGIs (Eckhardt et al., 2006; Bell et al., 2011).

\section{ENZYMES OF DNA METHYLATION}

Methylation of DNA is catalyzed by three families of DNA methyltransferases: DNMT1, DNMT2, and DNMT3 (Jeltsch, 2006a).

DNMT1 is responsible for life-long maintenance of DNA methylation during cell division - it copies DNA methylation 
marks from the original to the nascent strand during DNA replication (Tang etal., 2009). Consistent with this role, DNMT1 is expressed ubiquitously in proliferative cells (Jurkowska et al., 2011); it has a 30- to 40-fold binding preference for hemimethylated than unmethylated CpGs (Jeltsch, 2006b). DNMT1 does not appear to have a specific target DNA sequence (Jeltsch, 2006a). Instead, through its interaction with the DNA replication machinery, DNMT1 is tethered to the replication fork where it methylates DNA using a hemi-methylated template (Jurkowska et al., 2011).

DNMT2 catalyzes methylation of small RNA molecules, instead of DNA, but it has some residual de novo DNA methyltransferase activity (Hermann et al., 2003; Jurkowski et al., 2008).

The DNMT3 family of DNA methyltransferases has three members: DNMT3A, DNMT3B, and DNMT3L. DNMT3A and DNMT3B are bona fide de novo methyltransferases that methylate DNA without a template (Tang et al., 2009). DNMT3L lacks DNA methyltransferase activity but it co-localizes with DNMT3A and DNMT3B and enhances their activity (Hata et al., 2002; Jurkowska et al., 2011). In contrast to DNMT1, which maintains life-long expression in proliferative cells, DNMT3A and DNMT3B are expressed mainly during early embryogenesis (though they have some specialized functions in adulthood, such as maintaining self-renewal of hematopoietic stem cells (Tadokoro et al., 2007), cooperating with DNMT1 in silencing tumor suppressor genes in colorectal cancer cells (Rhee et al., 2002), or regulating synaptic plasticity in the brain (Feng etal., 2010a; LaPlant et al., 2010). Also in contrast to DNMT1, DNMT3A and DNMT3B appear to have preferences for certain DNA sequences. For example, they prefer CpGs flanked by upstream purine bases and downstream pyrimidine bases (Handa and Jeltsch, 2005). In addition, they form tetrameric complexes with DNMT3L (Jia et al., 2007) and the structural orientation of active sites and fixed spacing between adjacent complexes allow simultaneous methylation of CpGs separated by 8-10 bp (Jurkowska et al., 2008, 2011). These intrinsic properties of de novo DNMTs may influence how DNA methylation patterns are established during early embryogenesis.

\section{FUNCTION OF DNA METHYLATION}

The main functions of DNA methylation are the regulation of gene expression and protection of genome integrity.

\section{Regulation of gene expression}

Methylation of DNA can modulate transcription of DNA to RNA by influencing DNA binding of proteins that initiate and perform DNA transcription (Portela and Esteller, 2010; Shukla et al., 2011). Methylation of DNA may do so either directly, through physical impediment of protein binding, or indirectly, through chromatin remodeling and its effect on DNA accessibility for proteins that regulate DNA transcription (Portela and Esteller, 2010). DNA methylation impacts not only the quantity but also the form of produced RNA; the latter effect is mediated by DNA methylation modulating the use of alternative promoters (Maunakea et al., 2010) and splice sites (Shukla et al., 2011).

Methylation of DNA has traditionally been considered an inhibitor of DNA transcription. This effect is best understood in the context of gene promoters where DNA methylation can impair physical binding of transcription enhancers and promote the recruitment of methyl-CpG-binding domain proteins that increase chromatin condensation and thus decrease the DNA accessibility for the transcriptional machinery (Portela and Esteller, 2010). Consistent with this inhibitory effect of DNA methylation on DNA transcription, CpGs within $1 \mathrm{~kb}$ of transcription start sites are generally hypomethylated (Bell et al., 2011; Jjingo etal., 2012). The inverse correlation of DNA methylation and gene expression may also depend on CGI context; CpG sites outside of CGIs are two times more likely to be correlated with gene expression than $\mathrm{CpG}$ sites within CGIs (Numata et al., 2012).

In contrast to DNA methylation in gene promoters, DNA methylation in gene bodies has been associated with enhanced DNA transcription (Aran et al., 2011; McGowan et al., 2011). Genebody DNA methylation is common in ubiquitously expressed genes and correlates positively with gene expression at a genomewide level (Hellman and Chess, 2007; Suzuki and Bird, 2008; Ball et al., 2009). It has been proposed that, rather than a cause of enhanced gene expression, gene-body DNA methylation may be its consequence (Zilberman et al., 2007; Jjingo et al., 2012). During early embryogenesis - when DNA methylation patterns are being established - an open chromatin structure of chromosomal regions containing actively transcribed genes allows DNMTs to access and methylate DNA. Within these regions, CpGs in promoters of actively transcribed genes are occupied by DNA-binding transcription factors and cannot be methylated, but CpGs in gene bodies that are not occupied by these factors can and are methylated (Jjingo etal., 2012). This pattern of DNA methylation (low in promoters and high in gene bodies) established during early embryogenesis is then copied throughout life and, through low promoter methylation, may contribute to higher expression of these genes (Jeltsch, 2006a; Ball et al., 2009). Assuming this happens for a large number of genes, gene-body methylation then correlates positively with DNA transcription at a genome-wide level (Jjingo et al., 2012). In addition to this indirect positive relationship between genebody methylation and genome-wide gene expression, gene-body methylation may be involved in suppression of DNA transcription directly by, for example, inhibiting alternative promoters embedded in gene bodies (Maunakea et al., 2010), or by impeding RNA-polymerase transit and transcription elongation (Zilberman et al., 2007; Deaton et al., 2011).

\section{Protection of genome integrity}

Methylation of DNA protects the genome's integrity by suppressing mobility of transposable elements (TEs). TEs are repetitive DNA sequences that have the ability to integrate into new chromosome locations, through either "cut-and-paste" or "copyand-paste" mechanisms (Levin and Moran, 2011). TEs, like non-transposable repetitive elements, are hypermethylated, resulting in their transcriptional silencing (Law and Jacobsen, 2010). Since the transposition machinery requires TE-encoded enzymes, suppression of TE transcription by DNA methylation effectively prevents translocations and gene disruptions (Levin and Moran, 2011). Loss of DNA methylation allows for TE reactivation and transposition (Tsukahara et al., 2009). 


\section{DNA METHYLATION CHANGES DURING DEVELOPMENT AND AGING}

During embryogenesis, DNA methylation is a highly dynamic trait (Eckhardt et al., 2006; Talens et al., 2010; Figure 1). Immediately after fertilization, the zygote genome undergoes global depletion of DNA methylation, reaching its lowest levels at the pre-implantation-blastocyst stage - the stage when pluripotent embryonic stem cells form most of the inner cell mass of the embryo (Feng et al., 2010b). Post-implantation, DNA methylation patterns are re-established and become relatively stable and similar to those found in adult somatic cells (Smith et al., 2012). Mono-allelic DNA methylation within imprinted genes escapes the global erasure/re-establishment to preserve parent-of-origin expression (Bartolomei, 2009). Furthermore, the cells that differentiate into primordial germ cells undergo an additional round of global erasure/re-establishment to reflect the sex of the embryo (Feng et al., 2010b). In both somatic and primordial germ cells, the global erasure of DNA methylation is mediated by cytosine deaminases (Bhutani et al., 2010; Popp et al., 2010) and the reestablishment of DNA methylation patterns is catalyzed mainly by de novo DNA methyltransferases, DNMT3A and DNMT3B (Okano et al., 1999; Kato et al., 2007).
The erasure/re-establishment of DNA methylation during early embryogenesis aids in the process of cell differentiation (Epsztejn-Litman et al., 2008). Global erasure of DNA methylation activates the expression of pluripotency genes, which promote the development of embryonic stem cells, which are cells capable of generating any tissue in the body (Straussman et al., 2009). These pluripotency genes are re-methylated upon the initial stages of cell differentiation (Epsztejn-Litman et al., 2008), at which point cell-specific DNA methylation patterns begin to develop (Straussman et al., 2009), enabling cells to have specific structures and functions.

After embryonic re-establishment, DNA methylation patterns are maintained by DNMT1 during successive cell divisions (i.e., DNA methylation marks are copied from original to nascent strands during DNA replication) and, as such, are relatively stable throughout life (particularly during young and middleaged adulthood). This maintenance of DNA methylation is not perfect, however. It has been observed that older monozygotic twin pairs demonstrate greater DNA methylation differences than younger monozygotic twin pairs (Fraga et al., 2005). This so-called epigenetic drift might be due to the accumulation of small errors in

\section{Zygote $\rightarrow$ Implantation}

- Global DNA de-methylation occurs -Passively during cell division and actively by cytosine deamination

-DNA de-methylation allows embryonic stem cells to become pluripotent

-Mono-allelic DNA methylation within imprinted genes is not erased
Fetal development $\rightarrow$ Adulthood

-Established DNA methylome is maintained trough consecutive cell divisions

- Critical role of DNMT1 in maintenance of DNAmethylation patterns during DNA replication -Aging can modify DNA methylation through epigenetic drift (accumulation of small defects in transmitting and maintaining DNA methylation )
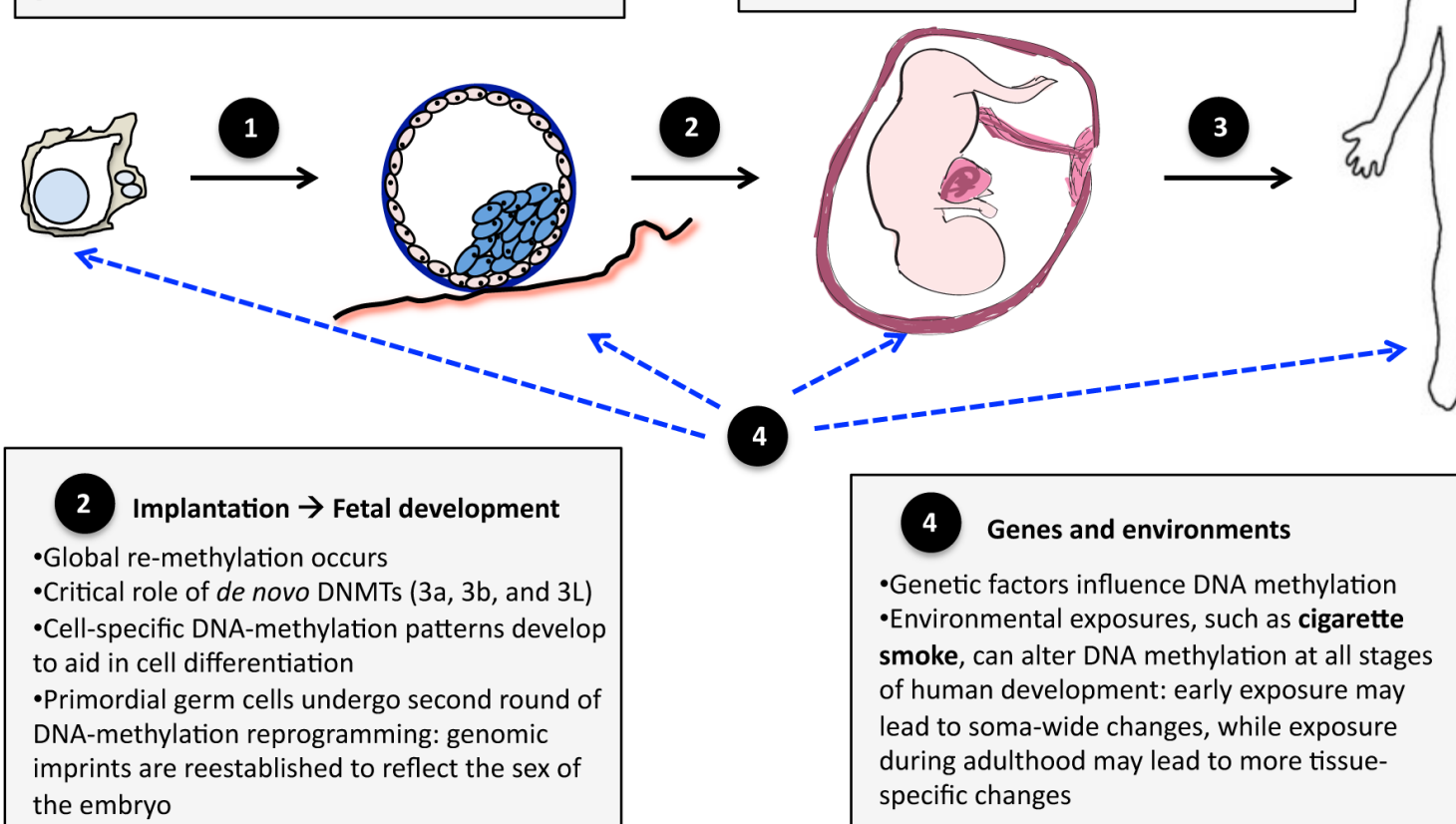

FIGURE 1 | DNA methylation during development and aging. The changes in the human methylome can be divided into three stages: (1) transition from zygote to pre-implantation blastocyst, (2) transition from

implanted blastocyst to early fetal development, and (3) transition into adult life. Genes and the environment (4) influence DNA methylation patterns at each of these stages. 
copying DNA methylation marks during successive cell divisions (Martin, 2005). The differences between twins were greater for pairs that spent less of their lifetime together or exhibited more different lifestyles, suggesting that environmental factors play a role in epigenetic drift (Fraga et al., 2005). In addition, senescence is associated with global demethylation of the genome (Bjornsson et al., 2008; Bollati et al., 2009), possibly due to decreasing DNMT1 activity (Lopatina et al., 2002).

\section{TISSUE-SPECIFICITY OF DNA METHYLATION PATTERNS}

A considerable similarity in DNA methylation levels exists across different tissues. By bisulfite-DNA sequencing of human chromosomes in 12 different tissues, it was estimated that only about $5-15 \%$ of CpGs are methylated in a tissue-specific manner (Eckhardt et al., 2006). Furthermore, these differential CpGs are more likely to be found between developmentally distant tissues, such as liver (derived from endoderm) and kidney (derived from mesoderm; Pai et al., 2011) than between developmentally close tissues, such as various types of lymphocytes (all derived from mesoderm; Eckhardt et al., 2006).

\section{SEX DIFFERENCES IN DNA METHYLATION}

A high degree of similarity in DNA methylation patterns also exists between males and females (Eckhardt et al., 2006; Talens et al., 2010). Nonetheless, some sex differences do exist. The most notable is the hypermethylation of gene promoters on $\mathrm{X}$ chromosome that occurs only in females (Hellman and Chess, 2007). This process is initiated during the blastocyst stage (coinciding with global re-methylation of autosomes); it is mediated by DNMT1 and DNMT3B (Hansen et al., 2000; Csankovszki et al., 2001), and executed at random with respect to the parental origin of the inactivated X chromosome (Escamilla-Del-Arenal et al., 2011). Another sex difference pertains to the frequency of DNA methylation aberrations, which are more frequent in male than female aborted or stillborn fetuses (Pliushch et al., 2010). DNA methylation aberrations are also more easily induced in males than females by early environments, such as prenatal exposure to cigarette smoke or a lack of folate (Hoyo et al., 2011; Murphy et al., 2012a).

Taken together, DNA methylation at any given $\mathrm{CpG}$ is the result of multiple processes that are orchestrated as a developmental cascade involving, first, global demethylation after fertilization, then, cell/tissue-specific re-methylation during very early embryogenesis and, finally, maintenance of DNA methylation throughout the remainder of life. Each of these processes depends on the supply of methyl groups and the catalytic activity of DNA methylation enzymes (and associated machinery), both of which are regulated by genetic and environmental factors.

\section{GENETIC AND ENVIRONMENTAL INFLUENCES ON DNA METHYLATION}

Methylation of DNA at a given $\mathrm{CpG}$ is a quantitative trait regulated by a complex interplay of genetic and environmental factors. Twin and family-based studies suggest that a significant proportion of inter-individual variability in DNA methylation is determined genetically (Bjornsson et al., 2008; Kaminsky et al., 2009). DNA methylation is more similar in monozygotic than dizygotic twins
(Kaminsky et al., 2009) and age-related changes in DNA methylation during adulthood show familial clustering with estimated heritability of $>70 \%$ (Bjornsson et al., 2008).

\section{GENETIC INFLUENCES ON DNA METHYLATION}

The contribution of genetic factors to DNA methylation may vary across individual CpGs. Some CpGs are located directly on single nucleotide polymorphisms (SNPs) and, if their Cs or Gs are mutated into other nucleotides, they are not methylated. In these CpGs, DNA methylation behaves as a monogenic trait, being "high" in non-mutant homozygotes, "intermediate" in heterozygotes and "low" in mutant homozygotes. Interestingly, such effects of sequence variation can spread across neighboring CpGs and thus contribute to the observed correlated nature of DNA methylation at neighboring CpGs (Bell et al., 2011). For example, at a CpG located on rs10846023 (a T/C SNP), the level of DNA methylation is highly allele-specific; methylation beta on the $\mathrm{T}$ allele was close to $0 \%$, whereas methylation beta on the $\mathrm{C}$ allele was $>60 \%$ (Shoemaker et al., 2010). This effect of allele specificity was exhibited at nearby CpGs, spanning over 500 bp (Shoemaker et al., 2010).

Further support for DNA methylation being in part determined genetically comes from genome-wide association studies (GWAS) testing genotype-phenotype associations between $>600,000$ SNPs and DNA methylation at $>25,000$ CpGs (Bell et al., 2011; Numata et al., 2012). These GWAS identified a large number of SNPs $(\sim 3,000)$ associated with the level of DNA methylation at various CpGs; most of them were located within 2-kb regions of interrogated CpGs, but some were further apart or even on different chromosomes (Bell et al., 2011; Numata et al., 2012). Of note, given the large number of statistical tests typically performed in a GWAS of DNA methylation (i.e., 600,000 SNPs $\times$ 25,000 CpGs) and the need for correction for multiple comparisons, only SNPs with very large effects (explaining $>20 \%$ of variance at a given $\mathrm{CpG}$ ) have been reported, thus leaving out undiscovered SNPs with smaller but likely biologically meaningful effects.

Other than creating or abolishing a CpG by mutation, the mechanisms of how DNA variants modulate DNA methylation are not well understood. The results of the above GWAS suggest that some mechanisms may be regional, whereas others may be more global, or even genome-wide. The SNPs associated with DNA methylation at nearby CpGs are likely to exert regional effects; these may be related to specific sequence variants interfering with the action of the DNA methylation machinery (Handa and Jeltsch, 2005). For example, in vitro studies suggest that the de novo methyltransferases DNMT3A and DNMT3B may have intrinsic preferences for certain flanking sequences (Jurkowska et al., 2011) and that the DNMT3A/DNMT3L complex favors methylation of $\mathrm{CpG}$ distributed periodically and separated by distances of 8-10 bp (Jia et al., 2007). The SNPs associated with DNA methylation at multiple distant $\mathrm{CpGs}$ located across large regions and on different chromosomes are likely exerting more global effects; these may be related to sequence variants modulating the expression or catalytic activity of enzymes involved in the process of DNA methylation. For example, a recent GWAS identified a SNP associated with global level of DNA methylation, which was located in the gene encoding disco-interacting protein 2 homolog 
B (DIP2B; Bell et al., 2011); this protein contains a DNA methyltransferase 1-associated protein 1-binding domain and, as such, may be part of the DNA methylation machinery (Winnepenninckx et al., 2007). In the same study, a weaker association with global DNA methylation levels was found near DNMT1, which encodes the key enzyme for DNA methylation maintenance (described in Section "DNA Methylation"; Bell et al., 2011). Apart from GWAS, candidate-gene studies revealed additional genes associated with global DNA methylation level; these were the methylenetetrahydrofolate reductase gene (MTHFR; Castro et al., 2004), which encodes an enzyme involved in the generation of methyl groups required for DNA methylation (Foley et al., 2009), and DNMT3B (Murphy et al., 2012b), which is one of the two key de novo DNA methyltransferases (described in Section "DNA Methylation”).

\section{ENVIRONMENTAL INFLUENCES ON DNA METHYLATION}

Methylation of DNA may also be modified by environmental factors (Terry etal., 2011). Environments acting during early embryogenesis (e.g., when global erasure and re-establishment of DNA methylation occur) may induce extensive, soma-wide modifications of DNA methylation, whereas environments acting later during life are more likely to induce less extensive, tissuespecific modifications of DNA methylation (Figure 1). The former may be involved in fetal programing of adult disorders (Suter and Aagaard, 2012), whereas the latter may play a role in tissue-specific carcinogenesis (for example, Ehrlich and Lacey, 2013). One environment implicated in both these effects is exposure to cigarette smoke.

\section{EXPOSURE TO CIGARETTE SMOKE}

Cigarette smoking is still common, despite well-publicized adverse consequences on health (reviewed in Sherman, 1991). In Canada and the USA, for example, $\sim 20 \%$ of all adults and $\sim 10 \%$ of pregnant women smoke at present (Centers for Disease Control and Prevention, 2011; Health Canada, 2011; Haghighi et al., 2013). It is well established that (1) active cigarette smoking is a major risk factor of cancer, cardiovascular disease, and chronic obstructive pulmonary disease (Kannel et al., 1987; Bartecchi et al., 1994; Doll et al., 1994) and (2) prenatal exposure to cigarette smoke causes fetal growth restriction prenatally, increases risk for sudden infant death syndrome postnatally and promotes the development of addictive behavior, immune-system abnormalities, obesity and associated cardiometabolic diseases postnatally (Power et al., 2010; Syme et al., 2010; Winans et al., 2011; Haghighi et al., 2013). Part of these effects may be mediated through cigarette smoke-induced modulations of DNA methylation.

Cigarette smoke is considered one of the most powerful environmental modifiers of DNA methylation (Breitling et al., 2011). The specific mechanisms of how cigarette smoke may alter DNA methylation are becoming better understood (Figure 2). First, cigarette smoke may modulate it through DNA damage and subsequent recruitment of DNMTs. Carcinogens in cigarette smoke, such as arsenic, chromium, formaldehyde, polycyclic aromatic hydrocarbons, and nitrosamines (Smith and Hansch, 2000; Suter et al., 2010), can damage DNA by causing double-stranded breaks, as shown in mouse embryonic stem cells exposed to cigarettesmoke condensate (Huang etal., 2012). In these experiments, survivor cells display a high capacity for DNA repair and normal karyotypes (Huang et al., 2012). The DNA repair sites recruit DNMT1 (Mortusewicz et al., 2005), which methylates CpGs adjacent to the repaired nucleotides (Cuozzo etal., 2007). Second, cigarette smoke may also modulate DNA methylation through nicotine effects on gene expression (Lee and D'Alonzo, 1993). Nicotine binds to and activates the nicotinic acetylcholine receptors (present abundantly in the central and peripheral nervous systems) and thus increases intracellular calcium and leads to downstream activation of cAMP response element-binding protein, a key transcription factor for many genes (Shen and Yakel, 2009). Acting possibly through this pathway, nicotine has been shown to downregulate DNMT1 mRNA and protein expression in mouse brain neurons (Satta et al., 2008). Third, cigarette smoke may alter DNA methylation indirectly through the modulation of expression and activity of DNA-binding factors. It has been demonstrated, for example, that cigarette-smoke condensate increases Sp1 expression and binding to DNA in lung epithelial cells (Mercer etal., 2009; Di et al., 2012). Sp1 is a common transcription factor that binds to GC-rich motifs in gene promoters (Kadonaga et al., 1987) and plays a key role in early development; as such, it may prevent de novo methylation of $\mathrm{CpGs}$ within these motifs during early embryogenesis (Han et al., 2001). Fourth, cigarette smoke may alter DNA methylation via hypoxia - cigarette smoke contains carbon monoxide that binds to hemoglobin (competitively with oxygen) and thus decreases tissue oxygenation (Olson, 1984). Hypoxia, in turn, leads to the HIF-1 $\alpha$-dependent upregulation of methionine adenosyltransferase $2 \mathrm{~A}$, which is an enzyme that synthesizes $S$-adenosylmethionine, a major biological methyl donor critical for DNA methylation processes (Liu et al., 2011).

Below we review studies investigating the alterations of DNA methylation associated with current and prenatal exposures to cigarette smoke. We focus mainly on studies employing epigenome-wide technologies (see Box 1).

\section{CURRENT EXPOSURE TO CIGARETTE SMOKE AND DNA METHYLATION}

Several epigenome-wide studies have examined whether cigarette smoking is associated with modifications of DNA methylation. One of the first ones was conducted with the Illumina 27K Methylation BeadChip, which interrogates DNA methylation at $>27,000$ CpG sites located mostly in gene promoters (Breitling et al., 2011). This study, conducted with DNA from peripheral lymphocytes, identified a differentially (smokers vs. non-smokers) methylated CpG site in the protease-activated receptor 4 gene (F2RL3), achieving Bonferroni-corrected significance threshold $\left(p<1.81 \times 10^{-6}\right)$ for multiple testing of $>27,000 \mathrm{CpGs}$ (Breitling et al., 2011). At this site, DNA methylation was significantly lower in smokers than non-smokers ( $\%$ methylation difference $\left.=12 \% ; p=2.7 \times 10^{-31}\right)$ and correlated negatively with the number of smoked cigarettes and positively with the duration of smoking abstinence (Breitling et al., 2011). Similar exposure-related differences in the methylation of this gene were also seen in another independent study ( $\%$ methylation difference $=8 \% ; p=8.4 \times 10^{-11}$; Shenker et al., 2012). Interestingly, F2RL3 is involved in platelet activation and intimal hyperplasia and inflammation - DNA methylation changes in this gene may represent a mechanistic link 


\section{Hypoxia}

-Nicotine induces uteroplacental underperfusion, decreasing oxygen supply to the fetus

-HIF-1 $\alpha$ enhances expression of MAT2A, which modulates methyl group availability
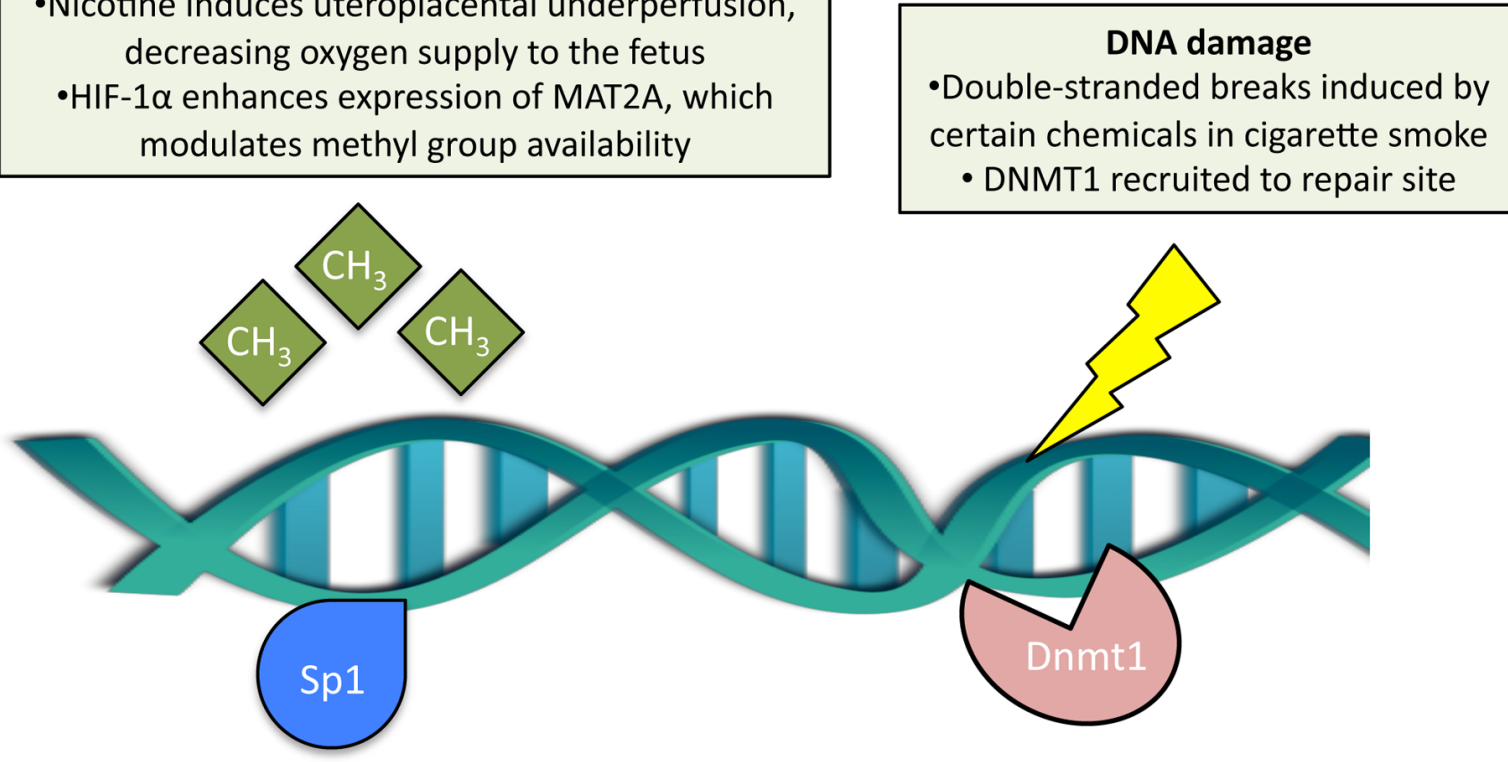

DNA-binding proteins

- Sp1 activated by cigarette smoke increases DNA binding

- It protects $\mathrm{CpG}$ sites from methylation
FIGURE 2 | Effects of cigarette smoke exposure on DNA methylation. Cigarette smoke has been shown to modulate DNA methyltransferase 1 (DNMT1) content, both at the transcript and protein level, and enzymatic activity separately in different cell types. Double-stranded DNA breaks may be induced by cigarette smoke, which subsequently recruits DNMT1 adjacent to the repair site. DNA-binding proteins, such as Sp1, are activated by cigarette smoke and protect $\mathrm{CpG}$ sites from de novo methylation. In the context of prenatal exposure, cigarette smoke induces hypoxia in the embryo, which in turn modulates methyl group availability. between cigarette smoking and cardiovascular disease (Breitling et al., 2011).

More recent studies have been conducted with the Illumina 450K Methylation BeadChip, which interrogates $>450,000 \mathrm{CpG}$ sites located not only in gene promoters but also in gene bodies and intergenic regions (Sandoval et al., 2011). These studies replicated the previous F2RL3 findings and identified further CpG sites methylated differentially between smokers and non-smokers. Among the latter ones, most significant were those found in the body of the aryl hydrocarbon receptor repressor gene (AHRR; Monick et al., 2012; Shenker et al., 2012). At these sites, DNA methylation was significantly lower in smokers than non-smokers in two different tissues, at a Bonferroni-corrected significance threshold of $p<10^{-7}$, namely the lungs (\% methylation difference $\left.=34 \% ; p=1.97 \times 10^{-9}\right)$ and peripheral lymphocytes $\left(\%\right.$ methylation difference $=17 \% ; p=2.3 \times 10^{-15}$; Monick et al., 2012; Shenker et al., 2012). When tested in the lungs, DNA methylation correlated inversely with the levels of AHRR mRNA in both smokers and non-smokers (Monick et al., 2012). AHRR encodes a transcription factor that inhibits the aryl hydrocarbon receptor pathway, which enhances the expression of detoxification (xenobiotic-metabolizing) enzymes of environmental pollutants, such as polycyclic aromatic hydrocarbons contained in cigarette smoke (Opitz etal., 2011). Thus, cigarette smoking-induced decreases in AHRR DNA methylation and related increases in $A H R R$ expression may compromise the body's capacity to metabolize and thus remove harmful environmental chemicals, and as such may represent a potential mechanism of increased risk of carcinogenesis in smokers.

Finally, it should be noted that cigarette smoking may alter DNA methylation in multiple tissues (Hammons et al., 1999; Peters et al., 2007; Suzuki et al., 2007; Satta etal., 2008), and some of these alterations may differ between the tissues. Most of the current investigations, however, utilized DNA from peripheral lymphocytes or buccal cells only (due to the ease of their sampling) and, thus, did not examine this potential tissue variability. Furthermore, several epigenome-wide studies of disease outcomes closely related to cigarette smoking have been conducted (e.g., lung cancer; Carvalho etal., 2012 and chronic obstructive pulmonary disease; Qiu et al., 2012), but they did not examine effects of cigarette smoking per se. As such, these studies are outside the scope of the present review. Epigenetic signatures of disease 


\section{BOX 1 | Methods of measuring DNA methylation.}

\section{Locus-specific DNA methylation}

- Bisulfite pyrosequencing (Frommer etal., 1992): Detects DNA methylation at single- $\mathrm{CpG}$ resolution over a short span of DNA $(<1 \mathrm{~kb})$ and requires only a small amount of DNA for analysis. It is a quantitative sequencing method used for a pre-selected genomic region.

\section{Locus-independent global DNA methylation}

- Bisulfite pyrosequencing of repetitive DNA elements (Breton etal., 2009): Methylation of repetitive DNA sequences, such as long interspersed elements (LINEs), short interspersed elements (SINEs), and satellite DNA, have been used as markers of global DNA methylation, as these elements are abundantly found throughout the genome.

- ELISA-based methylation assay (Guerrero-Preston etal., 2010): Uses methylcytosine-specific antibodies to quantify the relative DNA methylation between samples.

- $\left[{ }^{3} \mathrm{H}\right]-$-methyl acceptance assay (Terry etal., 2008): Relies on Sss/ prokaryotic methylase to incorporate $\left[{ }^{3} \mathrm{H}\right]$-labeled methyl groups at all unmethylated $\mathrm{CpGs}$. Amount of incorporated $\left[{ }^{3} \mathrm{H}\right]$ is inversely proportional to endogenous DNA methylation.

- Luminometric methylation assay (LUMA; Karimi etal., 2006): Relies on genomic cleavage by methylation-sensitive and insensitive restriction enzymes; difference in amount of cleavage between these two types of enzymes is a readout for global methylation.

\section{Epigenome-wide DNA methylation}

- Reduced representation bisulfite sequencing (RRBS; Gu etal., 2011): Uses next-generation sequencing technology on bisulfiteconverted DNA fragments, enriched at CpG-dense regions of the genome to reduce amount of sequencing required.

- Illumina 450K Methylation BeadChip (Dedeurwaerder etal., 2011): A robust high-throughput methylation microarray, providing coverage to over $480,000 \mathrm{CpG}$ sites across $96 \%$ of $\mathrm{CpG}$ islands and $99 \%$ of RefSeq genes across the genome.

- Illumina GoldenGate Assay for Methylation (McRonald etal., 2009): This platform utilizes pre-selected $\mathrm{CpG}$ sites within genes relevant for specific diseases or pathways, such as the GoldenGate Methylation Cancer Panel I, which spans 1,505 CpG loci from 807 cancer-related genes.

outcomes closely related to cigarette smoking have been reviewed recently in Sundar et al. (2011).

\section{PRENATAL CHRONIC EXPOSURE TO CIGARETTE SMOKE AND DNA METHYLATION}

Cigarette smoke may influence the fetus in a number of ways, some of which may also alter DNA methylation. The latter include certain chemicals in cigarette smoke (e.g., carcinogenic xenobiotics and nicotine) that can pass through the placenta to the developing embryo and fetus (Lambers and Clark, 1996). The passage of some of these chemicals is diminished by the detoxifying capacity of placenta (i.e., it metabolizes harmful xenobiotics; Sanyal et al., 1994; Suter and Aagaard, 2012). One molecule involved in this function is cytochrome P450 (CYP1A1), which is a phase-I enzyme in a two-phase detoxifying pathway (Nebert and Dalton, 2006). Prenatal exposure to cigarette smoke has been associated with lower DNA methylation of CYP1A1 at CpG sites surrounding the xenobiotic response-element, which is a major transcriptional enhancer of CYP1A1 expression (Suter et al., 2010). It was also associated with higher CYP1A1 mRNA expression (Suter et al., 2010). Genespecific effects of prenatal exposure to cigarette smoke on placental DNA methylation and mRNA have also been seen in another study employing, side-by-side, the Illumina 27K Methylation BeadChip and the IlluminaHG-12 gene-expression array (Suter et al., 2011). The authors searched for genes in which promoter DNA methylation is correlated with mRNA expression. They identified a significantly larger number of such genes in exposed $(n=438)$ than non-exposed placentas ( $n=25$; Suter et al., 2011). Interestingly, many of these genes encoded molecules involved in hypoxia response- and oxidative stress-regulating pathways (e.g., HIF-1 $\alpha$ signaling; Suter et al., 2011). Whether these DNA methylation (and mRNA) modifications develop as functional adaptations to the greater need to detoxify xenobiotics and/or respond to hypoxia in the exposed placentas remains to be determined.

Prenatal exposure to cigarette smoke has been associated with altered DNA methylation not only in placentas but also in offspring tissues. Studies examining DNA methylation globally showed that exposed vs. non-exposed individuals exhibit lower level of DNA methylation at birth (cord serum, ELISA-based method; GuerreroPreston et al., 2010) as well as during childhood (buccal cells, bisulfite conversion, and pyrosequencing of DNA repetitive elements; Breton et al., 2009) and middle-aged adulthood (peripheral blood cells, $\left[{ }^{3} \mathrm{H}\right]$-methyl acceptance assay; Terry et al., 2008). The most recent study of individual CpGs conducted with the Illumina $450 \mathrm{~K}$ Methylation BeadChip suggests that exposure is associated not only with global changes but also with changes at specific $\mathrm{CpG}$ sites (Joubert et al., 2012). Examining DNA methylation in cells from cord blood and assessing prenatal cigarette-smoke exposure by circulating maternal cotinine (a metabolite of nicotine and a stable biomarker of cigarette smoking), the authors identified 26 epigenome-wide significant CpGs that were differentially methylated between exposed and non-exposed individuals (Joubert et al., 2012). Among these, the most significant were those located in the xenobiotic-detoxifying genes, namely AHRR and CYP1A1; as discussed above, these two genes have been shown previously to be differentially methylated by cigarette smoke. Similar to the current chronic exposure to cigarette smoke in adult smokers, the CpGs in AHRR showed lower DNA methylation in exposed vs. non-exposed, but in contrast to prenatal chronic exposure to cigarette smoke in placentas, the CpGs in CYP1A1 demonstrated higher DNA methylation in exposed vs. non-exposed (Joubert et al., 2012). The differentially methylated CpGs in CYP1A1 in cord blood were the same as those in placenta (Suter et al., 2010). The reasons for these seemingly opposite effects of prenatal exposure to cigarette smoke on DNA methylation in placental and fetal tissues are not clear at present. It is of note, however, that placental (vs. fetal) tissues are globally hypomethylated, suggesting potential differences in the regulation of DNA methylation between the two types of tissues (Santos et al., 2002; Fuke et al., 2004; Novakovic et al., 2010; Macaulay et al., 2011).

\section{SUMMARY AND FUTURE DIRECTIONS}

Cigarette smoking continues to be a major health problem, and understanding the mechanisms of its effects is an important area of research. DNA methylation represents an epigenetic modification 
that can mediate the effects of cigarette smoke on gene expression, and ultimately disease-relevant phenotypes. Prenatal chronic exposure to cigarette smoke is an adverse environmental stimulus at a time where the DNA methylome of the offspring is highly dynamic and the genome-wide methylation patterns develop; as such, these changes are likely soma-wide and maintained throughout life. Current cigarette smoking occurs at a time when DNA methylation patterns are already established, but need to be properly maintained during cell divisions. Since cigarette smoke is known to modulate expression and activity of the maintenance methyltransferase DNMT1, actively dividing cells may be more susceptible to exposure-mediated defects in DNA methylation; this may in part explain the link between smoking and cancer.

Recent technological developments allow for the interrogation of $\mathrm{CpG}$ methylation status across the genome, and this has uncovered associated $\mathrm{CpG}$ sites within candidate genes including those that have not been previously implicated in cigarette smoking (Joubert et al., 2012). Remarkably, in both prenatal and current cigarette smoke exposure, similar genes, such as those involved

\section{REFERENCES}

Aran, D., Toperoff, G., Rosenberg, M., and Hellman, A. (2011). Replication timing-related and gene bodyspecific methylation of active human genes. Hum. Mol. Genet. 20, 670-680. doi: $10.1093 / \mathrm{hmg} / \mathrm{ddq} 513$

Ball, M. P., Li, J. B., Gao, Y., Lee, J. H., Leproust, E. M., Park, I. H., et al. (2009). Targeted and genome-scale strategies reveal gene-body methylation signatures in human cells. Nat. Biotechnol. 27, 361-368. doi: 10.1038/nbt.1533

Bartecchi, C. E., Mackenzie, T. D. and Schrier, R. W. (1994). The human costs of tobacco use (1). N. Engl. J. Med. 330, 907-912. doi: 10.1056/NEJM199403313301307

Bartolomei, M. S. (2009). Genomic imprinting: employing and avoiding epigenetic processes. Genes Dev. 23, 2124-2133. doi: 10.1101/gad. 1841409

Bell, J. T., Pai, A. A., Pickrell, J. K., Gaffney, D. J., Pique-Regi, R., Degner, J. F., et al. (2011). DNA methylation patterns associate with genetic and gene expression variation in HapMap cell lines. Genome Biol. 12, R10. doi: 10.1186/gb-2011-12-1-r10

Bhutani, N., Brady, J. J., Damian, M., Sacco, A., Corbel, S. Y., and Blau, H. M. (2010). Reprogramming towards pluripotency requires AID-dependent DNA demethylation. Nature 463, 1042-1047. doi: 10.1038/ nature 08752

Bibikova, M., Barnes, B., Tsan, C., Ho, V., Klotzle, B., Le, J. M., et al. (2011). High density DNA methylation array with single $\mathrm{CpG}$ site resolution. Genomics 98, 288-295. doi: 10.1016/ j.ygeno.2011.07.007
Bjornsson, H. T., Sigurdsson, M. I., Fallin, M. D., Irizarry, R. A., Aspelund, T., Cui, H., et al. (2008). Intra-individual change over time in DNA methylation with familial clustering. JAMA 299, 28772883. doi: 10.1001/jama.299.24 2877

Bollati, V., Schwartz, J., Wright, R., Litonjua, A., Tarantini, L., Suh, H. etal. (2009). Decline in genomic DNA methylation through aging in a cohort of elderly subjects. Mech. Ageing Dev. 130, 234-239. doi: 10.1016/ j.mad.2008.12.003

Breitling, L. P., Yang, R., Korn, B., Burwinkel, B., and Brenner, H. (2011). Tobacco-smoking-related differential DNA methylation: $27 \mathrm{~K}$ discovery and replication. Am. J. Hum. Genet. 88, 450-457. doi: 10.1016/ j.ajhg.2011.03.003

Breton, C. V., Byun, H. M., Wenten, M., Pan, F., Yang, A., and Gilliland, F. D. (2009). Prenatal tobacco smoke exposure affects global and gene-specific DNA methylation. Am. J. Respir. Crit. Care Med. 180 462-467. doi: 10.1164/rccm.200901$0135 \mathrm{OC}$

Carvalho, R. H., Haberle, V., Hou, J., Van Gent, T., Thongjuea, S., Van Ijcken, W., et al. (2012). Genome-wide DNA methylation profiling of non-small cell lung carcinomas. Epigenet. Chromatin 5, 9. doi: 10.1186/1756-89355-9

Castro, R., Rivera, I., Ravasco, P., Camilo, M. E., Jakobs, C. Blom, H. J., etal. (2004). 5,10methylenetetrahydrofolate reductase (MTHFR) 677C $\rightarrow \mathrm{T}$ and $1298 \mathrm{~A} \rightarrow \mathrm{C}$ mutations are associated with DNA hypomethylation.

in chemical detoxification (AHRR, CYP1A1), are differentially methylated, suggesting that smoking effects might be targeted to specific regions of the epigenome. Cigarette smoking may also have shared global consequences, as both prenatal and current exposures are associated with epigenome hypomethylation (Guerrero-Preston et al., 2010; Shigaki et al., 2012). In medicine, there is a growing practice of using the individualized genome to understand a patient's health and disease, but interpreting such information is dependent on epigenetics, such as DNA methylation. "Epigenotyping" patients to complement genomic data may be necessary in the near future.

\section{ACKNOWLEDGMENTS}

The authors would like to thank Dr. Tomas Paus (Rotman Research Institute, University of Toronto, Toronto, Canada) and Dr. Luigi Bouchard (Department of Biochemistry, Université de Sherbrooke, Sherbrooke, Canada) for their helpful comments on the manuscript. The Canadian Institutes of Health Research and the McLaughlin Centre, University of Toronto supported this work.

J. Med. Genet. 41, 454-458. doi: 10.1136/jmg.2003.017244

Centers for Disease Control and Prevention. (2011). Vital signs: current cigarette smoking among adults aged $\geq 18$ years - United States, 20052010. MMWR Morb. Mortal. Wkly. Rep. 60, 1207-1212.

Csankovszki, G., Nagy, A., and Jaenisch, R. (2001). Synergism of Xist RNA, DNA methylation, and histone hypoacetylation in maintaining X chromosome inactivation. J. Cell Biol. 153, 773-784. doi: 10.1083/jcb.153.4.773

Cuozzo, C., Porcellini, A., Angrisano, T., Morano, A., Lee, B., Di Pardo, A., et al. (2007). DNA damage, homology-directed repair, and DNA methylation. PLoS Genet. 3:e110. doi: 10.1371/journal.pgen. 0030110

Dahl, C., Gronbaek, K., and Guldberg, P. (2011). Advances in DNA methylation: 5-hydroxymethylcytosine revisited. Clin. Chim. Acta 412, 831-836. doi: 10.1016/j.cca.2011.02.013

Deaton, A. M., Webb, S., Kerr, A. R., Illingworth, R. S., Guy, J. Andrews, R., et al. (2011). Cell typespecific DNA methylation at intragenic $\mathrm{CpG}$ islands in the immune system. Genome Res. 21, 1074-1086. doi: $10.1101 /$ gr.118703.110

Dedeurwaerder, S., Defrance, M., Calonne, E., Denis, H., Sotiriou, C. and Fuks, F. (2011). Evaluation of the Infinium Methylation $450 \mathrm{~K}$ technology. Epigenomics 3, 771-784. doi: 10.2217/epi.11.105

Di, Y. P., Zhao, J., and Harper, R. (2012). Cigarette smoke induces MUC5AC protein expression through the activation of $\mathrm{Spl}$. J.
Biol. Chem. 287, 27948-27958. doi: 10.1074/jbc.M111.334375

Doll, R., Peto, R., Wheatley, K., Gray, R., and Sutherland, I. (1994). Mortality in relation to smoking: 40 years' observations on male British doctors. BMJ 309, 901-911. doi: 10.1136/bmj.309.6959.901

Eckhardt, F., Lewin, J., Cortese, R., Rakyan, V. K., Attwood, J., Burger, M., et al. (2006). DNA methylation profiling of human chromosomes 6 , 20 and 22. Nat. Genet. 38, 1378-1385. doi: 10.1038/ng1909

Ehrlich, M., and Lacey, M. (2013). DNA hypomethylation and hemimethylation in cancer. Adv. Exp. Med. Biol. 754,31-56. doi: 10.1007/978-1-44199967-2_2

Epsztejn-Litman, S., Feldman, N., AbuRemaileh, M., Shufaro, Y., Gerson, A., Ueda, J., et al. (2008). De novo DNA methylation promoted by G9a prevents reprogramming of embryonically silenced genes. Nat. Struct. Mol. Biol. 15, 1176-1183. doi: 10.1038/nsmb.1476

Escamilla-Del-Arenal, M., Da Rocha, S. T., and Heard, E. (2011). Evolutionary diversity and developmental regulation of $\mathrm{X}$-chromosome inactivation. Hum. Genet. 130, 307-327. doi: 10.1007/s00439-0111029-2

Feng, J., Zhou, Y., Campbell, S. L., Le, T., Li, E., Sweatt, J. D., et al. (2010a). Dnmt1 and Dnmt3a maintain DNA methylation and regulate synaptic function in adult forebrain neurons. Nat. Neurosci. 13, 423-430. doi: $10.1038 / \mathrm{nn} .2514$

Feng, S., Jacobsen, S. E., and Reik, W. (2010b). Epigenetic reprogramming in plant and animal 
development. Science 330, 622-627. doi: $10.1126 /$ science. 1190614

Ficz, G., Branco, M. R., Seisenberger, S., Santos, F., Krueger, F., Hore, T. A., etal. (2011). Dynamic regulation of 5-hydroxymethylcytosine in mouse ES cells and during differentiation. Nature 473, 398-402. doi: 10.1038 /nature 10008

Foley, D. L., Craig, J. M., Morley, R., Olsson, C. A., Dwyer, T., Smith, K., et al. (2009). Prospects for epigenetic epidemiology. Am. J. Epidemiol. 169, 389-400. doi: 10.1093/aje/ kwn380

Fraga, M. F., Ballestar, E., Paz, M. F., Ropero, S., Setien, F., Ballestar, M. L., et al. (2005). Epigenetic differences arise during the lifetime of monozygotic twins. Proc. Natl. Acad. Sci. U.S.A. 102, 10604-10609. doi: 10.1073/pnas.0500398102

Frommer, M., Mcdonald, L. E., Millar, D. S., Collis, C. M., Watt, F., Grigg, G. W., et al. (1992). A genomic sequencing protocol that yields a positive display of 5-methylcytosine residues in individual DNA strands. Proc. Natl. Acad. Sci. U.S.A. 89, 1827-1831. doi: 10.1073/pnas.89.5.1827

Fuke, C., Shimabukuro, M., Petronis, A., Sugimoto, J., Oda, T., Miura, K., et al. (2004). Age related changes in 5-methylcytosine content in human peripheral leukocytes and placentas: an HPLC-based study. Ann. Hum. Genet. 68, 196204. doi: $10.1046 / j .1529-8817.2004$. 00081.x

Gu, H., Smith, Z. D., Bock, C., Boyle, P. Gnirke, A., and Meissner, A. (2011). Preparation of reduced representation bisulfite sequencing libraries for genome-scale DNA methylation profiling. Nat. Protoc. 6, 468-481. doi: 10.1038/nprot.2010.190

Guerrero-Preston, R., Goldman, L. R., Brebi-Mieville, P., Ili-Gangas, C., Lebron, C., Witter, F. R., et al. (2010). Global DNA hypomethylation is associated with in utero exposure to cotinine and perfluorinated alkyl compounds. Epigenetics 5, 539546. doi: 10.4161/epi.5.6.12378

Haghighi, A., Schwartz, D. H., Abrahamowicz, M., Leonard, G. T., Perron, M., Richer, L., et al. (2013). Prenatal exposure to maternal cigarette smoking, amygdala volume, and fat intake in adolescence. JAMA Psychiatry 70, 98-105. doi: 10.1001/ archgenpsychiatry.2012.1101

Hammons, G. J., Yan, Y., Lopatina, N. G., Jin, B., Wise, C., Blann, E. B., et al. (1999). Increased expression of hepatic DNA methyltransferase in smokers. Cell Biol. Toxicol. 15, 389-394. doi: 10.1023/A:1007658000971
Han, L., Lin, I. G., and Hsieh, C. L. (2001). Protein binding protects sites on stable episomes and in the chromosome from de novo methylation. Mol. Cell. Biol. 21, 3416-3424. doi: 10.1128/MCB.21.10.3416-3424. 2001

Han, L., Su, B., Li, W. H., and Zhao, Z. (2008). CpG island density and its correlations with genomic features in mammalian genomes. Genome Biol. 9, R79. doi: 10.1186/gb-2008-95-r79

Handa, V., and Jeltsch, A. (2005). Profound flanking sequence preference of Dnmt3a and Dnmt3b mammalian DNA methyltransferases shape the human epigenome. J. Mol. Biol. 348, 1103-1112. doi: 10.1016/ j.jmb.2005.02.044

Hansen, R. S., Stoger, R., Wijmenga, C., Stanek, A. M., Canfield, T. K., Luo, P., et al. (2000). Escape from gene silencing in ICF syndrome: evidence for advanced replication time as a major determinant. Hum. Mol. Genet. 9, 2575-2587. doi: 10.1093/hmg/9.18.2575

Hata, K., Okano, M., Lei, H., and Li, E. (2002). Dnmt3L cooperates with the Dnmt3 family of de novo DNA methyltransferases to establish maternal imprints in mice. Development 129, 1983-1993.

Health Canada. (2011). Canadian Tobacco Use Monitoring Survey (CTUMS) 2011. Ottawa: Health Canada.

Hellman, A., and Chess, A. (2007). Gene body-specific methylation on the active $\mathrm{X}$ chromosome. Science 315 , 1141-1143. doi: 10.1126/science. 1136352

Hermann, A., Schmitt, S., and Jeltsch, A. (2003). The human Dnmt2 has residual DNA-(cytosineC5) methyltransferase activity. J. Biol. Chem. 278, 31717-31721. doi: 10.1074/jbc.M305448200

Hoyo, C., Murtha, A. P., Schildkraut, J. M., Jirtle, R. L., Demark-Wahnefried, W., Forman, M. R., et al. (2011). Methylation variation at IGF2 differentially methylated regions and maternal folic acid use before and during pregnancy. Epigenetics 6, 928-936. doi: 10.4161/epi.6.7. 16263

Huang, J., Okuka, M., Lu, W., Tsibris, J. C., Mclean, M. P., Keefe, D. L., et al. (2012). Telomere shortening and DNA damage of embryonic stem cells induced by cigarette smoke. Reprod. Toxicol. 35, 89-95. doi: 10.1016/ j.reprotox.2012.07.003

Jeltsch, A. (2006a). Molecular enzymology of mammalian DNA methyltransferases. Curr. Top. Microbiol.
Immunol. 301, 203-225. doi: 10.1007/3-540-31390-7_7

Jeltsch, A. (2006b). On the enzymatic properties of Dnmt1: specificity, processivity, mechanism of linear diffusion and allosteric regulation of the enzyme. Epigenetics 1, 63-66. doi: 10.4161/epi.1.2.2767

Jia, D., Jurkowska, R. Z., Zhang, X., Jeltsch, A., and Cheng, X. (2007). Structure of Dnmt3a bound to Dnmt3L suggests a model for de novo DNA methylation. Nature 449, 248-251. doi: 10.1038/nature06146

Jjingo, D., Conley, A. B., Yi, S. V., Lunyak, V. V., and Jordan, I. K. (2012). On the presence and role of human gene-body DNA methylation. Oncotarget 3, 462-474. doi: 10.1038 /nature 08514

Joubert, B. R., Haberg, S. E., Nilsen, R. M., Wang, X., Vollset, S. E., Murphy, S. K., et al. (2012). 450K epigenomewide scan identifies differential DNA methylation in newborns related to maternal smoking during pregnancy. Environ. Health Perspect. 120, 1425 1431. doi: 10.1289/ehp.1205412

Jurkowska, R. Z., Anspach, N., Urbanke, C., Jia, D., Reinhardt, R., Nellen, W., et al. (2008). Formation of nucleoprotein filaments by mammalian DNA methyltransferase Dnmt3a in complex with regulator Dnmt3L. Nucleic Acids Res. 36, 6656-6663. doi: 10.1093/nar/gkn747

Jurkowska, R. Z., Jurkowski, T. P., and Jeltsch, A. (2011). Structure and function of mammalian DNA methyltransferases. Chembiochem 12, 206-222. doi: 10.1002/cbic 201000195

Jurkowski, T. P., Meusburger, M., Phalke, S., Helm, M., Nellen, W., Reuter, G., and Jeltsch, A. (2008). Human DNMT2 methylates tRNA(Asp) molecules using a DNA methyltransferase-like catalytic mechanism. RNA 14, 1663-1670. doi: 10.1261/rna.970408

Kadonaga, J. T., Carner, K. R., Masiarz, F. R., and Tjian, R. (1987). Isolation of cDNA encoding transcription factor Sp1 and functional analysis of the DNA binding domain. Cell 51, 1079-1090. doi: 10.1016/00928674(87)90594-0

Kaminsky, Z. A., Tang, T., Wang, S. C., Ptak, C., Oh, G. H., Wong, A H., etal. (2009). DNA methylation profiles in monozygotic and dizygotic twins. Nat. Genet. 41, 240-245. doi 10.1038/ng.286

Kannel, W. B., D'Agostino, R. B., and Belanger, A. J. (1987). Fibrinogen, cigarette smoking, and risk of cardiovascular disease: insights from the Framingham Study. Am. Heart. J.
113, 1006-1010. doi: 10.1016/0002 8703(87)90063-9

Karimi, M., Johansson, S., Stach, D., Corcoran, M., Grander, D., Schalling, M., et al. (2006). LUMA (LUminometric Methylation Assay) a high throughput method to the analysis of genomic DNA methylation. Exp. Cell Res. 312, 19891995. doi: 10.1016/j.yexcr.2006. 03.006

Kato, Y., Kaneda, M., Hata, K., Kumaki, K., Hisano, M., Kohara, Y., et al. (2007). Role of the Dnmt3 family in de novo methylation of imprinted and repetitive sequences during male germ cell development in the mouse. Hum. Mol. Genet. 16, 2272-2280. doi: 10.1093/hmg/ddm 179

Lambers, D. S., and Clark, K. E. (1996). The maternal and fetal physiologic effects of nicotine. Semin. Perinatol. 20, 115-126. doi: 10.1016/S01460005(96)80079-6

Lander, E. S., Linton, L. M., Birren, B., Nusbaum, C., Zody, M. C., Baldwin, J., et al. (2001). Initial sequencing and analysis of the human genome. Nature 409, 860921. doi: 10.1038/35057062

LaPlant, Q., Vialou, V., Covington, H. E. III, Dumitriu, D., Feng, J., Warren, B. L., et al. (2010). Dnmt3a regulates emotional behavior and spine plasticity in the nucleus accumbens. Nat. Neurosci. 13, 1137-1143. doi: 10.1038/nn.2619

Law, J. A., and Jacobsen, S. E. (2010). Establishing, maintaining and modifying DNA methylation patterns in plants and animals. Nat. Rev. Genet. 11, 204-220. doi: 10.1038/nrg2719

Lee, E. W., and D'Alonzo, G. E. (1993). Cigarette smoking, nicotine addiction, and its pharmacologic treatment. Arch. Intern. Med. 153, 34-48. doi: 10.1001/archinte. 1993.00410010062005

Levin, H. L., and Moran, J. V. (2011). Dynamic interactions between transposable elements and their hosts. Nat. Rev. Genet. 12, 615-627. doi: 10.1038/nrg3030

Liu, Q., Liu, L., Zhao, Y., Zhang, J., Wang, D., Chen, J., et al. (2011). Hypoxia induces genomic DNA demethylation through the activation of HIF-1alpha and transcriptional upregulation of MAT2A in hepatoma cells. Mol. Cancer Ther. 10, 1113-1123. doi: 10.1158/15357163.MCT-10-1010

Lopatina, N., Haskell, J. F., Andrews, L. G., Poole, J. C., Saldanha, S., and Tollefsbol, T. (2002). Differential maintenance and de novo methylating activity by three DNA methyltransferases in aging 
and immortalized fibroblasts. $J$. Cell. Biochem. 84, 324-334. doi: 10.1002/jcb. 10015

Macaulay, E. C., Weeks, R. J., Andrews, S., and Morison, I. M. (2011). Hypomethylation of functional retrotransposon-derived genes in the human placenta. Mamm. Genome 22, 722-735. doi: 10.1007/ s00335-011-9355-1

Martin, G. M. (2005). Epigenetic drift in aging identical twins. Proc. Natl. Acad. Sci. U.S.A. 102, 10413-10414. doi: 10.1073/pnas. 0504743102

Maunakea, A. K., Nagarajan, R. P., Bilenky, M., Ballinger, T. J., D’Souza, C., Fouse, S. D., et al. (2010). Conserved role of intragenic DNA methylation in regulating alternative promoters. Nature 466, 253-257. doi: 10.1038 /nature09165

McGowan, P. O., Suderman, M., Sasaki, A., Huang, T. C., Hallett, M., Meaney, M. J., et al. (2011). Broad epigenetic signature of maternal care in the brain of adult rats. PLoS ONE 6:e14739. doi: 10.1371/journal.pone.0014739

McRonald, F. E., Morris, M. R., Gentle, D., Winchester, L., Baban, D. Ragoussis, J., etal. (2009). CpG methylation profiling in VHL related and VHL unrelated renal cell carcinoma. Mol. Cancer 8, 31. doi: 10.1186/1476-4598-8-31

Medvedeva, Y. A., Fridman, M. V., Oparina, N. J., Malko, D. B., Ermakova, E. O., Kulakovskiy, I. V., et al. (2010). Intergenic, gene terminal, and intragenic $\mathrm{CpG}$ islands in the human genome. BMC Genomics 11, 48. doi: 10.1186/1471-2164-11-48

Mercer, B. A., Wallace, A. M., Brinckerhoff, C. E., and D'Armiento, J. M. (2009). Identification of a cigarette smoke-responsive region in the distal MMP-1 promoter. Am. J. Respir. Cell Mol. Biol. 40, 4-12. doi: 10.1165/rcmb.2007-0310OC

Monick, M. M., Beach, S. R., Plume, J., Sears, R., Gerrard, M., Brody, G. H., et al. (2012). Coordinated changes in AHRR methylation in lymphoblasts and pulmonary macrophages from smokers. Am. J. Med. Genet. B Neuropsychiatr. Genet. 159B, 141-151. doi: 10.1002/ajmg.b.32021

Mortusewicz, O., Schermelleh, L., Walter, J., Cardoso, M. C., and Leonhardt, H. (2005). Recruitment of DNA methyltransferase I to DNA repair sites. Proc. Natl. Acad. Sci. U.S.A. 102, 8905-8909. doi: 10.1073/ pnas.0501034102

Murphy, S. K., Adigun, A., Huang, Z., Overcash, F., Wang, F., Jirtle, R. L., et al. (2012a). Gender-specific methylation differences in relation to prenatal exposure to cigarette smoke. Gene 494, 36-43. doi: 10.1016/j.gene.2011.11.062

Murphy, T. M., Mullins, N., Ryan, M., Foster, T., Kelly, C., Mcclelland, R., et al. (2012b). Genetic variation in DNMT3B and increased global DNA methylation is associated with suicide attempts in psychiatric patients. Genes Brain Behav. 12, 125-132. doi: 10.1111/j.1601-183X.2012.00865.x

Nebert, D. W., and Dalton, T. P. (2006). The role of cytochrome P450 enzymes in endogenous signalling pathways and environmental carcinogenesis. Nat. Rev. Cancer 6, 947-960. doi: 10.1038/nrc2015

Novakovic, B., Wong, N. C., Sibson, M., Ng, H. K., Morley, R., Manuelpillai, U., et al. (2010). DNA methylationmediated down-regulation of DNA methyltransferase-1 (DNMT1) is coincident with, but not essential for, global hypomethylation in human placenta. J. Biol. Chem. 285, 9583-9593. doi: 10.1074/jbc.M109. 064956

Numata, S., Ye, T., Hyde, T. M., GuitartNavarro, X., Tao, R., Wininger, M. et al. (2012). DNA methylation signatures in development and aging of the human prefrontal cortex. Am. J. Hum. Genet. 90, 260-272. doi: 10.1016/j.ajhg.2011.12.020

Okano, M., Bell, D. W., Haber, D. A., and Li, E. (1999). DNA methyltransferases Dnmt3a and Dnmt3b are essential for de novo methylation and mammalian development. Cell 99, 247-257. doi: 10.1016/S00928674(00)81656-6

Olson, K. R. (1984). Carbon monoxide poisoning: mechanisms, presentation, and controversies in management. J. Emerg. Med. 1, 233-243. doi: 10.1016/0736-4679(84)90078-7

Opitz, C. A., Litzenburger, U. M., Sahm, F., Ott, M., Tritschler, I., Trump, S., et al. (2011). An endogenous tumour-promoting ligand of the human aryl hydrocarbon receptor. Nature 478, 197-203. doi: 10.1038 /nature 10491

Pai, A. A., Bell, J. T., Marioni, J. C., Pritchard, J. K., and Gilad, Y. (2011). A genome-wide study of DNA methylation patterns and gene expression levels in multiple human and chimpanzee tissues. PLoS Genet. 7:e1001316. doi: 10.1371/ journal.pgen.1001316

Peters, I., Vaske, B., Albrecht, K., Kuczyk, M. A., Jonas, U., and Serth, J. (2007). Adiposity and age are statistically related to enhanced RASSF1A tumor suppressor gene promoter methylation in normal autopsy kidney tissue.
Cancer Epidemiol. Biomarkers Prev. 16, 2526-2532. doi: 10.1158/1055 9965.EPI-07-0203

Pliushch, G., Schneider, E., Weise, D., El Hajj, N., Tresch, A., Seidmann, L., etal. (2010). Extreme methylation values of imprinted genes in human abortions and stillbirths. Am. J. Pathol. 176, 1084-1090. doi: 10.2353/ajpath.2010.090764

Popp, C., Dean, W., Feng, S., Cokus, S. J., Andrews, S., Pellegrini, M. et al. (2010). Genome-wide erasure of DNA methylation in mouse primordial germ cells is affected by AID deficiency. Nature 463, 1101-1105. doi: 10.1038/nature08829

Portela, A., and Esteller, M. (2010). Epigenetic modifications and human disease. Nat. Biotechnol. 28, 10571068. doi: 10.1038/nbt.1685

Power, C., Atherton, K., and Thomas, C. (2010). Maternal smoking in pregnancy, adult adiposity and other risk factors for cardiovascular disease. Atherosclerosis 211, 643-648. doi: 10.1016/j.atherosclerosis.2010. 03.015

Qiu, W., Baccarelli, A., Carey, V. J., Boutaoui, N., Bacherman, H., Klanderman, B., et al. (2012). Variable DNA methylation is associated with chronic obstructive pulmonary disease and lung function. Am. J. Respir. Crit. Care Med. 185, 373-381. doi: 10.1164/rccm.201108-1382OC

Rakyan, V. K., Down, T. A., Balding, D. J., and Beck, S. (2011). Epigenomewide association studies for common human diseases. Nat. Rev. Genet. 12, 529-541. doi: 10.1038/ nrg3000

Rhee, I., Bachman, K. E., Park, B. H., Jair, K. W., Yen, R. W., Schuebel, K. E., et al. (2002). DNMT1 and DNMT3b cooperate to silence genes in human cancer cells. Nature 416, 552-556. doi: 10.1038/416552a

Sandoval, J., Heyn, H., Moran, S., Serra-Musach, J., Pujana, M. A., Bibikova, M., et al. (2011). Validation of a DNA methylation microarray for 450,000 CpG sites in the human genome. Epigenetics 6, 692-702. doi: 10.4161/epi.6.6.16196

Santos, F., Hendrich, B., Reik, W., and Dean, W. (2002). Dynamic reprogramming of DNA methylation in the early mouse embryo. Dev. Biol. 241, 172-182. doi: 10.1006/dbio. 2001.0501

Sanyal, M. K., Li, Y. L., and Belanger, K. (1994). Metabolism of polynuclear aromatic hydrocarbon in human term placenta influenced by cigarette smoke exposure. Reprod. Toxicol. 8, 411-418. doi: 10.1016/08906238(94)90081-7
Satta, R., Maloku, E., Zhubi, A., Pibiri, F., Hajos, M., Costa, E., and Guidotti, A. (2008). Nicotine decreases DNA methyltransferase 1 expression and glutamic acid decarboxylase 67 promoter methylation in GABAergic interneurons. Proc. Natl. Acad. Sci. U.S.A. 105, 16356-16361. doi: 10.1073/pnas.0808699105

Shen, J. X., and Yakel, J. L. (2009). Nicotinic acetylcholine receptor-mediated calcium signaling in the nervous system. Acta Pharmacol. Sin. 30, 673680. doi: 10.1038/aps.2009.64

Shenker, N. S., Polidoro, S., Van Veldhoven, K., Sacerdote, C., Ricceri, F., Birrell, M. A., et al. (2012). Epigenome-wide association study in the European Prospective Investigation into Cancer and Nutrition (EPIC-Turin) identifies novel genetic loci associated with smoking. Hum Mol Genet. 22, 843-851. doi: $10.1093 / \mathrm{hmg} / \mathrm{dds} 488$

Sherman, C. B. (1991). Health effects of cigarette smoking. Clin. Chest Med. 12, 643-658. doi: 10.5271/sjweh. 2066

Shigaki, H., Baba, Y., Watanabe, M., Iwagami, S., Miyake, K., Ishimoto, T., et al. (2012). LINE-1 hypomethylation in noncancerous esophageal mucosae is associated with smoking history. Ann. Surg. Oncol. 19, 42384243. doi: 10.1245/s10434-0122488-y

Shoemaker, R., Deng, J., Wang, W., and Zhang, K. (2010). Allele-specific methylation is prevalent and is contributed by CpG-SNPs in the human genome. Genome Res. 20, 883-889. doi: 10.1101/gr.104695.109

Shukla, S., Kavak, E., Gregory, M., Imashimizu, M., Shutinoski, B., Kashlev, M., et al. (2011). CTCFpromoted RNA polymerase II pausing links DNA methylation to splicing. Nature 479, 74-79. doi: 10.1038/ nature 10442

Smith, C. J., and Hansch, C. (2000). The relative toxicity of compounds in mainstream cigarette smoke condensate. Food Chem. Toxicol. 38, 637-646. doi: 10.1016/S02786915(00)00051-X

Smith, Z. D., Chan, M. M., Mikkelsen, T. S., Gu, H., Gnirke, A., Regev, A., et al. (2012). A unique regulatory phase of DNA methylation in the early mammalian embryo. Nature 484, 339-344. doi: $10.1038 /$ nature 10960

Straussman, R., Nejman, D., Roberts, D., Steinfeld, I., Blum, B., Benvenisty, N., et al. (2009). Developmental programming of $\mathrm{CpG}$ island methylation profiles in the human genome. Nat. Struct. Mol. Biol. 16, 564-571. doi: $10.1038 /$ nsmb. 1594 
Sundar, I. K., Mullapudi, N., Yao, H., Spivack, S. D., and Rahman, I. (2011). Lung cancer and its association with chronic obstructive pulmonary disease: update on nexus of epigenetics. Curr. Opin. Pulm. Med. 17, 279-285. doi: 10.1097/ MCP.0b013e3283477533

Suter, M., Abramovici, A., Showalter, L., Hu, M., Shope, C.D., Varner, M., et al. (2010). In utero tobacco exposure epigenetically modifies placental CYP1A1 expression. Metabolism 59, 1481-1490. doi: 10.1016/ j.metabol.2010.01.013

Suter, M., Ma, J., Harris, A., Patterson, L., Brown, K. A., Shope, C., et al. (2011). Maternal tobacco use modestly alters correlated epigenomewide placental DNA methylation and gene expression. Epigenetics 6, 1284 1294. doi: 10.4161/epi.6.11.17819

Suter, M. A., and Aagaard, K. (2012). What changes in DNA methylation take place in individuals exposed to maternal smoking in utero? Epigenomics 4, 115-118. doi: 10.2217/epi.12.7

Suzuki, M., Shigematsu, H., Shames, D. S., Sunaga, N., Takahashi, T., Shivapurkar, N., et al. (2007). Methylation and gene silencing of the Rasrelated GTPase gene in lung and breast cancers. Ann. Surg. Oncol. 14, 1397-1404. doi: 10.1245/s10434006-9089-6
Suzuki, M. M., and Bird, A. (2008). DNA methylation landscapes: provocative insights from epigenomics. Nat. Rev. Genet. 9, 465-476. doi: 10.1038/nrg2341

Syme, C., Abrahamowicz, M., Mahboubi, A., Leonard, G. T., Perron, M., Richer, L., etal. (2010). Prenatal exposure to maternal cigarette smoking and accumulation of intraabdominal fat during adolescence. Obesity (Silver Spring) 18, 1021-1025. doi: 10.1038/oby.2009.354

Tadokoro, Y., Ema, H., Okano, M., Li, E. and Nakauchi, H. (2007). De novo DNA methyltransferase is essential for self-renewal, but not for differentiation, in hematopoietic stem cells. J. Exp. Med. 204, 715-722. doi: 10.1084/jem.20060750

Talens, R. P., Boomsma, D. I., Tobi, E. W., Kremer, D., Jukema, J. W., Willemsen, G., et al. (2010). Variation, patterns, and temporal stability of DNA methylation: considerations for epigenetic epidemiology. FASEB J. 24, 3135-3144. doi: 10.1096/fj.09150490

Tang, M., Xu, W., Wang, Q., Xiao, W., and $\mathrm{Xu}, \mathrm{R}$. (2009). Potential of DNMT and its epigenetic regulation for lung cancer therapy. Curr. Genomics 10, 336-352. doi: 10.2174/138920209788920994

Terry, M. B., Delgado-Cruzata, L., VinRaviv, N., Wu, H. C., and Santella
R. M. (2011). DNA methylation in white blood cells: association with risk factors in epidemiologic studies. Epigenetics 6, 828-837. doi: 10.4161/epi.6.7.16500

Terry, M. B., Ferris, J. S., Pilsner, R., Flom, J. D., Tehranifar, P., Santella R. M., etal. (2008). Genomic DNA methylation among women in a multiethnic New York City birth cohort. Cancer Epidemiol. Biomarkers Prev. 17, 2306-2310. doi: 10.1158/10559965.EPI-08-0312

Tsukahara, S., Kobayashi, A., Kawabe, A., Mathieu, O., Miura, A., and Kakutani, T. (2009). Bursts of retrotransposition reproduced in Arabidopsis. Nature 461, 423-426. doi: 10.1038 /nature08351

Winans, B., Humble, M. C., and Lawrence, B. P. (2011). Environmental toxicants and the developing immune system: a missing link in the global battle against infectious disease? Reprod. Toxicol. 31, 327336. doi: 10.1016/j.reprotox.2010 09.004

Winnepenninckx, B., Debacker, K. Ramsay, J., Smeets, D., Smits, A., Fitzpatrick, D. R., et al. (2007). CGG-repeat expansion in the DIP2B gene is associated with the fragile site FRA12A on chromosome 12q13.1. Am. J. Hum. Genet. 80, 221-231. doi: 10.1086/ 510800
Zilberman, D., Gehring, M., Tran, R. K., Ballinger, T., and Henikoff, S. (2007). Genome-wide analysis of Arabidopsis thaliana DNA methylation uncovers an interdependence between methylation and transcription. Nat. Genet. 39, 61-69. doi: 10.1038/ ng1929

Conflict of Interest Statement: The authors declare that the research was conducted in the absence of any commercial or financial relationships that could be construed as a potential conflict of interest.

Received: 03 May 2013; accepted: 20 June 2013; published online: 17 July 2013.

Citation: Lee KWK and Pausova Z (2013) Cigarette smoking and DNA methylation. Front. Genet. 4:132. doi: 10.3389/ fgene.2013.00132

This article was submitted to Frontiers in Epigenomics and Epigenetics, a specialty of Frontiers in Genetics.

Copyright (C) 2013 Lee and Pausova.

This is an open-access article distributed under the terms of the Creative Commons Attribution License, which permits use, distribution and reproduction in other forums, provided the original authors and source are credited and subject to any copyright notices concerning any thirdparty graphics etc. 